\title{
Insecticide resistance in malaria vector mosquitoes at four localities in Ghana, West Africa
}

\author{
Richard H Hunt ${ }^{1,2}$, Godwin Fuseini ${ }^{3}$, Steve Knowles ${ }^{4}$, Joseph Stiles-Ocran ${ }^{4}$, Rolf Verster ${ }^{5}$, Maria L Kaiser ${ }^{1,2}$, \\ Kwang Shik Choi ${ }^{1,2}$, Lizette L Koekemoer ${ }^{1,2}$ and Maureen Coetzee ${ }^{1,2^{*}}$
}

\begin{abstract}
Background: Malaria vector control programmes that rely on insecticide-based interventions such as indoor house spraying with residual insecticides or insecticide treated bed nets, need to base their decision-making process on sound baseline data. More and more commercial entities in Africa, such as mining companies, are realising the value to staff productivity of controlling malaria transmission in their areas of operation.

This paper presents baseline entomological data obtained during surveys conducted for four mining operations in Ghana, West Africa.

Results: The vast majority of the samples were identified as Anopheles gambiae S form with only a few $\mathrm{M}$ form specimens being identified from Tarkwa. Plasmodium falciparum infection rates ranged from 4.5 to $8.6 \%$ in An. gambiae and 1.81 to $8.06 \%$ in An. funestus. High survival rates on standard WHO bioassay tests were recorded for all insecticide classes except the organophosphates that showed reasonable mortality at all locations (i.e. > 90\%). The West African kdr mutation was detected and showed high frequencies in all populations.
\end{abstract}

Conclusions: The data highlight the complexity of the situation prevailing in southern Ghana and the challenges facing the malaria vector control programmes in this region. Vector control programmes in Ghana need to carefully consider the resistance profiles of the local mosquito populations in order to base their resistance management strategies on sound scientific data.

\section{Background}

Malaria remains today the biggest killer of children in Africa [1] and it demands increased attention from control authorities in affected countries. Multi-national corporations operating in Africa recognize the burden malaria places on their staff and its impact on their commercial operations $[2,3]$. There is an increasing move by these multi-nationals to control malaria within the boundaries of their activities, and in many cases, extending this control to the surrounding communities $[4,5]$.

The traditional methods of protecting work-forces using fogging, prophylaxis, repellents and handing out insecticide treated bed nets to workers (ITNs), have clearly not resulted in the desired outcome and companies are now implementing malaria control through the use of indoor residual house spraying $[2,3]$. Key to the

\footnotetext{
* Correspondence: maureenc@nicd.ac.za

'Malaria Entomology Research Unit, School of Pathology, Faculty of Health

Sciences, University of the Witwatersrand, Johannesburg, South Africa

Full list of author information is available at the end of the article
}

success of these measures is knowledge of the local vector populations, the species identity, role in transmission and susceptibility to the four classes of insecticides approved by the World Health Organization for use in vector control. Baseline surveys to collect this information need to be carried out prior to implementation of malaria vector control interventions and on-going susceptibility surveys done to guard against the development of increasing insecticide resistance. This is becoming more important as insecticide resistance increases and spreads across Africa.

This paper reports on four such baseline surveys carried out at mining operations in Ghana, West Africa.

\section{Materials and methods \\ Study sites}

Ghana has a relatively high rainfall, situated between $5^{\circ}$ and $12^{\circ}$ North of the Equator with typical tropical temperatures. The vegetation at the sites sampled was dense degraded forest, mixed with agricultural land. Formal

\section{Biomed Central}


cultivation of cocoa and oil palm is interspersed with secondary forest and subsistence farming with cassava, maize, pineapples, etc. The following gold mining sites (Figure 1) were surveyed for a maximum of two weeks each between 2006-2010:

Obuasi: (6 $\left.6^{\circ} 11^{\prime} 36^{\prime \prime} \mathrm{N}, 1^{\circ} 39^{\prime} 29^{\prime \prime} \mathrm{W}\right)$, a town of approximately 150,000 people with local inhabitants living in and around the mining operations. Gold has been mined at Obuasi for over 100 years, much of it opencast mining. Originally owned by Ashanti Gold Mines, the mine is now operated by AngloGold/Ashanti who have instituted an extensive malaria control programme in the area for the past four years. The mosquitoes used in this survey were collected outside but adjacent to the Obuasi malaria vector control area in July 2010.

Tarkwa/Damang: (5¹8'N, $\left.1^{\circ} 59^{\prime} 32^{\prime \prime W}\right)$ Two new mines in this area operated by AngloGold/Ashanti and Randgold Resources were sampled in May 2007 and March 2009.

Ahafo: $\left(7^{\circ} 1^{\prime} 33^{\prime \prime} \mathrm{N}, 2^{\circ} 20^{\prime} 27^{\prime \prime} \mathrm{W}\right)$, a Newmont Mines operation, was sampled in December 2006 and June 2008.

Akyem: $\left(6^{\circ} 20^{\prime} 24^{\prime \prime} \mathrm{N}, 1^{\circ} 0^{\prime} 28^{\prime \prime} \mathrm{W}\right)$ also operated by Newmont Mines, was sampled in June 2006.

\section{Mosquito collections}

Local villages on the outskirts of the mining operations were visited and permission sought from the chief or local householders to search their houses for indoor resting mosquitoes. Houses were searched at random and those found to yield good numbers of mosquitoes were revisited repeatedly to ensure sufficient samples for the susceptibility tests. The collections were carried out in the mornings, usually up until midday except when mosquitoes were very scarce and collections had to be continued until mid-afternoon. All mosquitoes were collected by hand using an aspirator. Live mosquitoes were identified morphologically as belonging to either the Anopheles gambiae complex or the An. funestus subgroup and used in insecticide susceptibility tests. They were subsequently stored on dry silica gel for laboratory processing.

\section{WHO insecticide susceptibility tests}

The WHO protocol [6] was used for testing susceptibility to the four classes of insecticides approved for vector control (pyrethroids, carbamates, organophosphates and organochlorines) except that age and physiological status of the mosquitoes was unknown. Treated test papers with the WHO diagnostic dosages were supplied by the

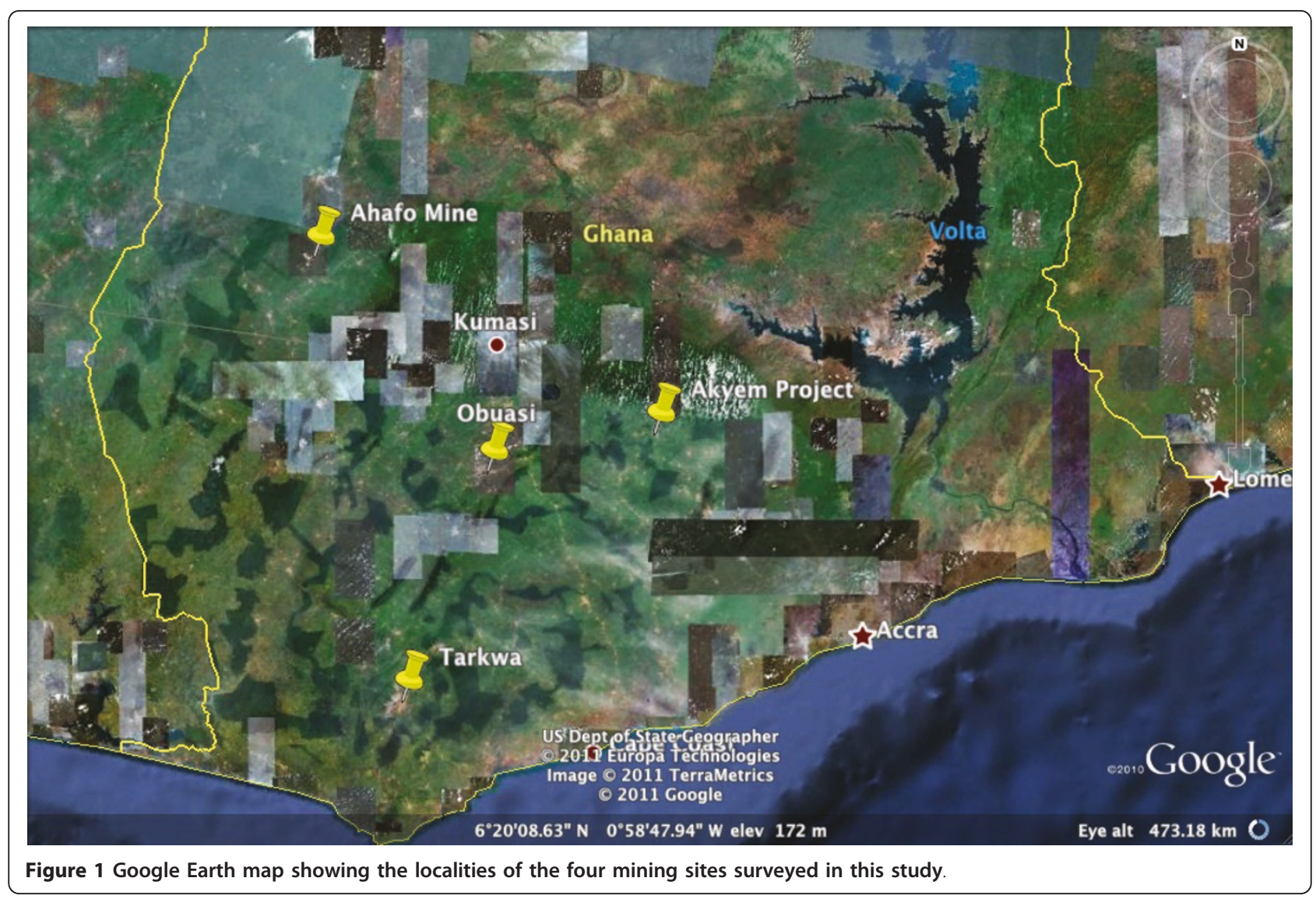


WHO Collaborating Centre in Penang, Malaysia (Table 2 ). Cohorts of $\sim 25$ mosquitoes were exposed for 1 hour to the discriminating dose (except for fenitrothion which requires a 2-hour exposure [7]) and held for 24 hours before final mortality was recorded. Control mosquitoes were handled in the same way but not exposed to insecticides and were added to the following day's collections to maximise the numbers tested, particularly when population density was low. Treated papers used in the field were tested in the laboratory using known susceptible mosquitoes to check for efficacy. The dead and alive mosquitoes were stored separately for species identification. WHO criteria for susceptibility are: 98$100 \%$ mortality - susceptible; 80 - 97\% mortality - resistance suspected and more investigations required; 0 $79 \%$ mortality - resistance confirmed.

\section{Laboratory analysis}

Mosquitoes were processed for species identification using the standard protocols for the An. gambiae complex [8,9] and the An. funestus group [10]. DNA was sourced from legs and wings of individual mosquitoes, either directly by grinding in buffer or using the Collins et al. extraction method [11]. Plasmodium falciparum parasite detection was carried out on dissected heads and thoraces of wild females using the enzyme-linked immunosorbent assay (ELISA) of Wirtz et al. [12]. The target site $k d r$ resistance mutations were assayed in mosquitoes exposed to pyrethroids (from the same DNA samples used for species identification) using the Taqman assay [13] for both East and West African mutations.

\section{Results}

The collection of indoor resting mosquitoes is very haphazard. Some houses in a village proved to be very productive with lots of mosquitoes present while other houses were not. Where treated bed nets in good condition were present, no mosquitoes were found in the bedrooms but on some occasions many mosquitoes were found resting inside the treated nets as well as in the adjacent living rooms, behind chairs or under tables, obviously avoiding the bedrooms due to the repellent effect of the treated bed nets [14].

Of the 1704 specimens of the An. gambiae complex (76.4\% of 2229) that were successfully identified, all but one was An. gambiae s.s. (a single An. arabiensis was identified from Ahafo). A subsample of these $(\mathrm{n}=862)$ was further characterised for the molecular forms and most were identified as the $\mathrm{S}$ molecular form (93.4\%) (Table 1). The molecular $M$ form was found in low numbers at Ahafo (6.8\% of 220) and Tarkwa (8.3\% of 459) while $M / S$ hybrids ( $n=4)$ were found only at Tarkwa. Anopheles funestus s.s. was the only member of the group identified from all localities (Table 1) except for a single specimen of $A n$. leesoni being found at Tarkwa.

The results of the susceptibility tests for $2229 A n$. gambiae s.l. are given in Table 2. In all cases the control mortality was less than $5 \%$, therefore not requiring adjustment with Abbott's formula [6]. Only the organophosphates showed good efficacy across all localities. High frequencies of resistance were recorded to pyrethroids, DDT and carbamates.

Table 1 Species identification and infection rates with Plasmodium falciparum circumsporozoite protein

\begin{tabular}{|c|c|c|c|c|c|c|}
\hline & funestus & arabiensis & gambiae s.s. & $S$ form & $M$ form & M/S hybrids \\
\hline \multicolumn{7}{|l|}{ Obuasi } \\
\hline No. Identified & 181 & 0 & 633 & 160 & 0 & 0 \\
\hline$\%$ infected & $\begin{array}{c}1.81^{*} \\
(4 / 221) \\
\end{array}$ & - & - & $\begin{array}{c}4.9^{*} \\
(13 / 267) \\
\end{array}$ & - & - \\
\hline \multicolumn{7}{|l|}{ Tarkwa } \\
\hline No. Identified & 78 & 0 & 475 & 417 & 38 & 4 \\
\hline$\%$ infected & $\begin{array}{c}3.8 \\
(3 / 78)\end{array}$ & - & $\begin{array}{c}4.7 \\
(17 / 365)\end{array}$ & $\begin{array}{c}4.5 \\
(15 / 333)\end{array}$ & $\begin{array}{c}6.25 \\
(2 / 32)\end{array}$ & 0 \\
\hline \multicolumn{7}{|l|}{ Ahafo } \\
\hline No. Identified & 34 & 1 & 461 & 205 & 15 & 0 \\
\hline$\%$ infected & $\begin{array}{c}2.9 \\
(1 / 34)\end{array}$ & - & $\begin{array}{c}8.3 \\
(19 / 229)\end{array}$ & $\begin{array}{c}8.6 \\
(16 / 187)\end{array}$ & $\begin{array}{c}15.4 \\
(2 / 13)\end{array}$ & - \\
\hline \multicolumn{7}{|l|}{ Akyem } \\
\hline No. Identified & 100 & 0 & 134 & 23 & 0 & 0 \\
\hline$\%$ infected & $\begin{array}{c}8.06 \\
(5 / 62)\end{array}$ & - & $\begin{array}{c}5.03 \\
(8 / 159)\end{array}$ & - & - & - \\
\hline
\end{tabular}

*These infectivity rates for Obuasi are taken from Coetzee et al. [2] for comparison as no ELISAs were carried out in 2010. 
Table 2 Results of exposure of wild Anopheles gambiae S form adults to insecticide treated papers using the WHO susceptibility test

\begin{tabular}{|c|c|c|c|c|c|}
\hline Locality & Insecticide class & Treated papers & Length of exposure & $\mathrm{N}$ & $\%$ Mortality 24 h post-exposure \\
\hline \multirow[t]{8}{*}{ Obuasi } & Pyrethroids & 0.05\% Deltamethrin & 1 hour & 64 & 89.1 \\
\hline & & 0.05\% Lambda-cyhalothrin & & 60 & 76.7 \\
\hline & & $0.15 \%$ Cyfluthrin & & 62 & 66.1 \\
\hline & & 0.75\% Permethrin & & 65 & 38.5 \\
\hline & Carbamates & $0.1 \%$ Bendiocarb & 1 hour & 61 & 93.4 \\
\hline & & $0.1 \%$ Propoxur & & 59 & 89.8 \\
\hline & Organophosphates & 1.0\% Fenitrothion & 2 hours & 60 & 96.7 \\
\hline & Organochlorines & $4.0 \% \mathrm{DDT}$ & 1 hour & 60 & 31.7 \\
\hline \multirow[t]{5}{*}{ Tarkwa } & Pyrethroids & 0.05\% Deltamethrin & 1 hour & 152 & 56.6 \\
\hline & Carbamates & $0.1 \%$ Bendiocarb & 1 hour & 113 & 74.3 \\
\hline & Organophosphates & 5.0\% Malathion & 1 hour & 210 & 98.6 \\
\hline & Organochlorines & $4.0 \% \mathrm{DDT}$ & 1 hour & 39 & 5.4 \\
\hline & & 4.0\% Dieldrin & & 14 & 0 \\
\hline \multirow[t]{5}{*}{ Akyem } & Pyrethroids & 0.05\% Deltamethrin & 1 hour & 173 & 75.1 \\
\hline & Carbamates & $0.1 \%$ Bendiocarb & 1 hour & 56 & 37.5 \\
\hline & Organophosphates & 5.0\% Malathion & 1 hour & 51 & 98.0 \\
\hline & Organochlorines & $4.0 \% \mathrm{DDT}$ & 1 hour & 53 & 5.7 \\
\hline & & 4.0\% Dieldrin & & 56 & 0 \\
\hline \multirow[t]{8}{*}{ Ahafo } & Pyrethroids & 0.05\% Deltamethrin & 1 hour & 186 & 45.1 \\
\hline & & 0.05\% Lambda-cyhalothrin & & 27 & 19.0 \\
\hline & & 0.75\% Permethrin & & 41 & 15.0 \\
\hline & Carbamates & $0.1 \%$ Bendiocarb & 1 hour & 178 & 77.6 \\
\hline & Organophosphates & 5.0\% Malathion & 1 hour & 171 & 95.4 \\
\hline & & 1.0\% Fenitrothion & 2 hours & 29 & 93.1 \\
\hline & Organochlorines & $4.0 \% \mathrm{DDT}$ & 1 hour & 100 & 3.1 \\
\hline & & 4.0\% Dieldrin & & 89 & 9.2 \\
\hline
\end{tabular}

Each day's exposures were run with at least 20 control mosquitoes. All controls showed $<5 \%$ mortality negating the need for the use of Abbott's formula [6].

All the An. funestus tested were $100 \%$ susceptible to deltamethrin $(\mathrm{n}=166)$ and malathion $(\mathrm{n}=251)$ at all four localities. Samples from three localities were tested on bendiocarb and resistance was detected only at Obuasi $(71.4 \%$ mortality, $\mathrm{n}=56$ [2]) but sample sizes were small at the other two sites (Tarkwa 53, Ahafo 3). DDT resistance was recorded at Obuasi $(60.9 \%$ mortality, $\mathrm{n}=23$ [2]) but insufficient samples for testing this insecticide were collected at the other sites.

The $k d r$ results are given in Table 3. As expected for An. gambiae $\mathrm{S}$ form in this area of West Africa, $k d r$ frequencies of the West African mutation, Leucine to Phenylalanine (L1014F), were high. The East African mutation, Leucine to Serine (L1014S), was not found in any of the specimens. Only five specimens of An. gambiae $\mathrm{M}$ form were available (from Tarkwa) for $k d r$ analysis and one was heterozygous for L1014F. The single $\mathrm{M} / \mathrm{S}$ hybrid that survived exposure to deltamethrin was homozygous RR.

The Plasmodium falciparum infection rates are given in Table 1 with Obuasi rates taken from the published literature [2]. Since only a small number of the Akyem An. gambiae s.s. were further identified to $\mathrm{S}$ form, the infection rate is given for "gambiae s.s.". The highest infection rates were recorded at Ahafo with over $8 \%$ for the $\mathrm{S}$ form and for the pooled "gambiae s.s.". The rate

Table 3 Knockdown resistance (Kdr) mutations (L1014F) in wild Anopheles gambiae, exposed to pyrethroid insecticide treated papers, from four localities in Ghana.

\begin{tabular}{lllllll}
\hline \hline Locality & Molecular form & $\begin{array}{l}\text { Resistant } \\
\text { Phenotype }\end{array}$ & RR & RS & SS & $\begin{array}{l}\text { \% } \boldsymbol{k d r} \\
\text { frequency }\end{array}$ \\
\hline Obuasi & S & Resistant & 11 & 1 & 0 & 95.8 \\
\hline Ahafo & S & Susceptible & 12 & 31 & 8 & 53.9 \\
\hline Akyem & S & Resistant & 20 & 0 & 0 & 100 \\
\hline & & Resistant & 17 & 18 & 3 & 68.4 \\
\hline Tarkwa & S & Susceptible & 14 & 7 & 6 & 64.8 \\
\hline & & Resistant & 56 & 1 & 0 & 99.1 \\
\hline
\end{tabular}

Genotypes RR = homozygous resistant, RS = heterozygous resistant/ susceptible and SS = homozygous susceptible. 
of $15 \%$ for the $\mathrm{M}$ form is to be treated with caution given the small sample size $(\mathrm{n}=13)$. Infection rates for An. funestus were much lower than An. gambiae at three of the four sites but higher for An. funestus at Akyem.

\section{Discussion}

The most common species encountered was An. gambiae $\mathrm{S}$ form, with very few $\mathrm{M}$ form and only one $A n$. arabiensis identified. Since the surveys were carried out on an ad hoc basis and usually timed for the middle of the rainy season, it is possible that the species composition varies depending on the time of the year. Anopheles funestus appeared to play a secondary role as a vector except at Akyem. It has a scattered distribution and was found only at sites where suitable swampy breeding habitats were abundant.

All insecticide exposures were carried out on wild female mosquitoes of unknown age and physiological status. Since knowing the age of the samples is useful for early detection of developing resistance, when resistance is already established and as high as in the present study, the age effect [15] becomes less important. Furthermore, while age effect has been demonstrated for DDT resistance in An. gambiae [15] and permethrin resistance in $A n$. funestus [16,17], it is not known whether the same applies to the organophosphates and carbamates for these species.

Mosquitoes of all physiological stages were collected, from unfed, to fully fed and gravid. The status of each individual was not recorded which means that susceptibility results give an overall view of resistance at each locality and cannot be broken down into physiological groups for comparison. Blood feeding is known to enhance the ability of female mosquitoes to survive exposure to some insecticides in some vector species (e. g. An. funestus [18]) but this may not be true for others (e.g. An. gambiae [19] except that this study did not expose freshly blood fed females but rather females that had been given a blood meal 6 days prior to exposure). The direct testing of wild females, as opposed to F-1 adults, is therefore pertinent for operational control even if it leads to an over-estimation of true (genetic) resistance in a population. Choice of insecticide for control interventions must be based on the number of mosquitoes that can survive exposure to any given insecticide regardless of age or physiological status.

Where very low mortality rates were recorded in the first round of testing, no further tests were conducted on that insecticide resulting in small sample sizes for some of the assays. In many cases mosquitoes were hard to come by and samples were used judiciously to provide maximum data on possible candidate insecticides for use in vector control by the various mines. As stated above, the surveys were conducted for only a short period at each locality, at times of the year that may not have been conducive to sampling other vector species such as $A n$. gambiae M form, An. arabiensis and $A n$. funestus. It is possible that these species can be found in greater numbers at other times of the year and that they may have different insecticide resistance profiles.

In general, the data confirm that resistance to one member of a class of insecticides is good evidence that resistance to other chemicals in the same class will occur. This is certainly the case with the pyrethroids tested here and is cause for concern. This insecticide group contains the only insecticides approved for use on bed nets. This valuable vector control strategy, where the person to be protected also serves as the bait to lure the mosquito into absorbing a lethal dose of insecticide, thus achieving the 'mass killing' effect [20], can no longer be relied upon. The diminishing effectiveness of this control tool comes at a time when international support for malaria control is significantly improving bed net coverage in Africa. During the study conducted at Ahafo in 2008 it was commonplace to find An. gambiae mosquitoes fully blood fed and resting inside longlasting nets during the day. These observations were not quantified, but the study by N'Guessan et al. [21] in neighbouring Benin provides data for this phenomenon and highlights a very real problem facing control programmes in this region of West Africa.

It is probable that the increasing use of ITNs in the area is impacting on the levels of resistance to pyrethroids and DDT. In 2000, Kristan et al. [22] collected An. gambiae s.s. (no molecular identifications done) from the Tarkwa area and reported 100\% 24-hr mortality on deltamethrin, $99.2 \%$ on permethrin and $94 \%$ after an $80 \mathrm{~min}$ exposure on DDT. This is in sharp contrast to the results presented here where 24-hr mortality was $56.6 \%$ on deltamethrin and only $5.4 \%$ on DDT from samples collected seven years later. It is obvious that this population has undergone considerable selection pressure and that resistance has increased exponentially over a very short period. On the other hand, the susceptibility results published for Obuasi in 2006 [2] show much lower mortality rates than the 2010 results given here for pyrethroids and carbamates. This may be due to the 2010 collections coming from rural villages outside of the mining area whereas the 2006 results were based on mosquitoes collected inside Obuasi town (before IRS was implemented) where inhabitants commonly use treated bed nets, mosquito coils and aerosols thereby increasing the selection pressure for resistance. The very low levels of mortality on $0.75 \%$ permethrin at Obuasi (38.5\%) and Ahafo (15\%) are of grave concern for the continued use of permethrin-treated bed nets. 
Yawson et al. [23] report high frequencies of the LeuPhe $k d r$ mutation in Ghana populations with $100 \%$ recorded from Kumasi which is just north of Obuasi and in close proximity to Ahafo and Akyem (Figure 1). In the present study, of 63 specimens from Obuasi processed for $k d r, 61.9 \%$ carried the Leu-Phe mutation, with $91.7 \%$ of the deltamethrin survivors being homozygous $k d r$. In Ahafo there was 100\% $k d r$ in 20 surviving individuals and in Akyem the overall frequency of $k d r$ was $66.9 \%$. Other recent studies in the vicinity of Accra also showed high $k d r$ frequencies [24-26]. The almost $100 \% k d r$ mutations recorded from Tarkwa, including those samples that were susceptible to deltamethrin, indicates that a metabolic mechanism must play a role in conferring resistance to pyrethroids and that $k d r$ on its own is not sufficient to confer resistance to an individual mosquito.

Working in northern Ghana near Navrongo, Anto et al. [27] reported worrying trends in An. gambiae and An. funestus survival on four pyrethroids and DDT. Despite their assertion that the vectors were all susceptible to these insecticides, in some instances survival was as high as $20 \%$. In the limited number of specimens that were processed in the laboratory, no $k d r$ mutations were found and all An. gambiae specimens were identified as the $\mathrm{M}$ molecular form. This suggests that a metabolic mechanism is responsible for the resistance observed in this region of Ghana as well.

\section{Conclusions}

The data presented here clearly indicate that insecticide resistance is widespread and often at very high frequencies, usually sufficiently high to preclude the use of several of the few insecticides approved by WHO for malaria control. Resistance management strategies are therefore critical for vector control programmes in this region.

\section{Acknowledgements \\ Staff and students of the VCRU are thanked for assistance with processing the laboratory specimens. Staff of the mining companies are thanked for assistance in the field collection of mosquitoes. Anonymous reviewers are thanked for constructive criticism. MC is funded by a DST/NRF South African Research Chair award. \\ Author details \\ 'Malaria Entomology Research Unit, School of Pathology, Faculty of Health Sciences, University of the Witwatersrand, Johannesburg, South Africa. ${ }^{2}$ Vector Control Reference Unit, National Institute for Communicable Diseases of the National Health Laboratory Service, Johannesburg, South Africa. ${ }^{3}$ Newmont Mines, Ahafo, Ghana. ${ }^{4}$ Malaria Control Programme, AngloGold/Ashanti, Obuasi, Ghana. ${ }^{5}$ Gold Fields Limited, Sandown, Johannesburg.}

\section{Authors' contributions}

$\mathrm{RHH}$ and $\mathrm{MC}$ were responsible for the design of the projects, data analysis and drafting the manuscript. GF, SK, JS-O and RV were responsible for the field logistics, data collection and drafting of the manuscript. MK, KSC and
LLK were responsible for the laboratory data collection and analysis and drafting of the manuscript. All authors read and approved the final version of the manuscript.

\section{Competing interests}

The authors declare that they have no competing interests.

Received: 27 March 2011 Accepted: 16 June 2011

Published: 16 June 2011

\section{References}

1. World Health Organization: World Malaria Report 2009. Geneva, Switzerland.

2. Coetzee $M$, Van Wyk P, Booman M, Koekemoer $L L$, Hunt RH: Insecticide resistance in malaria vector mosquitoes in a gold mining town in Ghana and implications for malaria control. Bull Soc Path Exot 2006, 99:400-403.

3. Sharp BL, Ridl FC, Govender D, Kuklinski J, Kleinschmidt I: Malaria vector control by indoor residual insecticide spraying on the tropical island of Bioko, Equatorial Guinea. Malar J 2007, 6:52.

4. Vezenegho SB, Koekemoer LL, Brooke BD, Hunt RH, Coetzee M: Malaria vector mosquito composition, sporozoite rate and insecticide susceptibility status in Guinea Conakry, West Africa. Med Vet Entomol 2009, 23:326-334.

5. Carnevale P, Toto JC, Guibert P, Keita M, Manguin S: Entomological survey and report of a knockdown resistance mutation in the malaria vector Anopheles gambiae from the Republic of Guinea. Trans $R$ Soc Trop Med Hyg 2010, 104:484-489.

6. World Health Organization: Test procedures for insecticide resistance monitoring in malaria vectors, bio-efficacy and persistence of insecticides on treated surfaces. WHO/CDS/CPC/MAL/98.12 Geneva, Switzerland; 1998

7. World Health Organization: Criteria and meaning of tests for determining the susceptibility or resistance is insects to insecticides. WHONBC/81.6 Geneva, Switzerland; 1981.

8. Scott JA, Brogdon WG, Collins FH: Identification of single specimens of the Anopheles gambiae complex by the polymerase chain reaction. Am J Trop Med Hyg 1993, 49:520-529.

9. Fanello C, Santolamazza F, Della Torre A: Simultaneous identification of species and molecular forms of the Anopheles gambiae complex by PCRRFLP. Med Vet Entomol 2002, 16:461-464.

10. Koekemoer LL, Kamau L, Hunt RH, Coetzee M: A cocktail polymerase chain reaction (PCR) assay to identify members of the Anopheles funestus (Diptera: Culicidae) group. Am J Trop Med Hyg 2002, 66:804-811.

11. Collins FH, Mendez MA, Rasmussen MO, Meheffey PC, Besansky NJ, Finnerty $\mathrm{V}$ : A ribosomal RNA gene probes differentiates members of the Anopheles gambiae complex. Am J Trop Med Hyg 1987, 37:37-41.

12. Wirtz RA, Sattabonkot J, Hall T, Burkot TR, Rosenberg R: Development and evaluation of an ELISA for plasmodium vivax-VK247 sporozoites. J Med Entomol 1992, 29:854-857.

13. Bass C, Nikou D, Donnelly MJ, Williamson MS, Ranson H, Ball A, Vontas J, Field LM: Detection of knockdown resistance (kdr) mutations in Anopheles gambiae: a comparison of two new high-throughput assays with existing methods. Malar J 2007, 6:111.

14. Dabire RK, Diabate A, Baldet T, Pare-Toe L, Guiguemde RT, Ouedraogo J-B, Skovmand $O$ : Personal protection of long lasting insecticide-treated nets in areas of Anopheles gambiae s.s. resistance to pyrethroids. Malar J 2006, 5:6.

15. Lines JD, Nassor NS: DDT resistance in Anopheles gambiae declines with mosquito age. Med Vet Entomol 1991, 5:261-265

16. Hunt RH, Brooke BD, Pillay C, Koekemoer LL, Coetzee M: Laboratory selection for and characteristics of pyrethroid resistance in the malaria vector Anopheles funestus. Med Vet Entomol 2005, 19:271-275.

17. Christian RN, Matambo TS, Spillings BL, Brooke BD, Coetzee M, Koekemoer LL: Age-related pyrethroid resistance and P450 gene expression in the major African malaria vector, Anopheles funestus (Diptera: Culicidae). Gen Mol Res 2011.

18. Spillings $B L$, Coetzee $M$, Koekemoer $L L$, Brooke BD: The effect of a single blood meal on the phenotypic expression of insecticide resistance in the major malaria vector Anopheles funestus. Malar J 2008, 7:226.

19. Rajatileka S, Burhani J, Ranson H: Mosquito age and susceptibility to insecticides. Trans R Soc Trop Med Hyg 2011, 105:247-253. 
20. Maxwell CA, Msuya E, Sudi M, Njunwa KJ, Carneiro IA, Curtis CF: Effect of community-wide use of insecticide-treated nets for 3-4 years on malarial morbidity in Tanzania. Trop Med Intnl Hlth 2002, 7:1003-1008.

21. N'Guessan R, Corbel V, Akogbeto M, Rowland M: Reduced efficacy of insecticide-treated nets and indoor residual spraying for malaria control in pyrethroid resistance area, Benin. Emerg Infect Dis 2007, 13:199-206.

22. Kristan M, Fleischmann H, Della Torre A, Stich A, Curtis CF: Pyrethroid resistance/susceptibility and differential urban/rural distribution of Anopheles arabiensis and An. gambiae s.s. malaria vectors in Nigeria and Ghana. Med Vet Entomol 2003, 17:326-332.

23. Yawson AE, McCall PJ, Wilson MD, Donnelly MJ: Species abundance and insecticide resistance of Anopheles gambiae in selected areas of Ghana and Burkina Faso. Med Vet Entomol 2004, 18:372-377.

24. Adasi $K$, Hemingway J: Susceptibility to three pyrethroids and detection of knockdown resistance mutation in Ghanaian Anopheles gambiae sensu stricto. J Vector Ecol 2008, 33:255-262.

25. Boakye DA, Adasi K, Appawu M, Brown CA, Wilson MD: Patterns of household insecticide use and pyrethroid resistance in Anopheles gambiae sensu stricto (Diptera: Culicidae) within the Accra metropolis of Ghana. Afr Entomol 2009, 17:125-130.

26. Santolamazza F, Calzetta M, Etang J, Barrese E, Dia I, Caccone A, Donnelly MJ, Petrarca V, Simard F, Pinto J, Della Torre A: Distribution of knock-down resistance mutations in Anopheles gambiae molecular forms in west and west-central Africa. Malar J 2008, 7:74.

27. Anto F, Asoala V, Anyorigiya T, Oduro A, Adjuik M, Owusu-Agyei S, Dery D, Appawu M, Dadzie S, Bimi L, Hodgson A: Insecticide resistance profiles for malaria vectors in the Kassena-Nankana district of Ghana. Malar J 2009, $8: 81$.

doi:10.1186/1756-3305-4-107

Cite this article as: Hunt et al: Insecticide resistance in malaria vector mosquitoes at four localities in Ghana, West Africa. Parasites \& Vectors 2011 4:107.

\section{Submit your next manuscript to BioMed Central and take full advantage of:}

- Convenient online submission

- Thorough peer review

- No space constraints or color figure charges

- Immediate publication on acceptance

- Inclusion in PubMed, CAS, Scopus and Google Scholar

- Research which is freely available for redistribution

Submit your manuscript at www.biomedcentral.com/submit 